Article

\title{
Development of Sustainable Recycling Investment Framework Considering Uncertain Demand and Nonlinear Recycling Cost
}

\author{
Hyunsoo Lee (1) \\ School of Industrial Engineering, Kumoh National Institute of Technology, Gumi 39177, Korea; hsl@kumoh.ac.kr; \\ Tel.: +82-54-478-7661
}

Received: 17 June 2019; Accepted: 17 July 2019; Published: 17 July 2019

\begin{abstract}
This paper presents a more active and efficient recycling investment strategy that considers the balances among the current production constraints, manufacturing profits, and recycling investments for a sustainable circular economy as compared to the current methods. While existing production planning has numerous uncertainties and nonlinear characteristics, the circular economy-based production planning constitutes more complex uncertainties and nonlinear characteristics that result from an uncertain return rate, demand uncertainties, and nonlinear return on investment costs. This paper suggests a stochastic nonlinear programming model-based active recycling investment framework so as to generate a more effective process plan to handle these characteristics. In the proposed framework, recycling investment strategies are quantitatively analyzed when considering uncertain demand and unclear production conditions. In addition, the effective solving techniques for the circular economy based production framework are obtained while using Monte-Carlo based sample average approximation and memetic algorithm. To prove the effectiveness of the proposed framework, it is implemented for a given system and the numerical analyses that were conducted for the various sustainable manufacturing scenarios.
\end{abstract}

Keywords: recycling investment strategy; demand uncertainty; Stochastic nonlinear Programming; Monte-Carlo based sample average approximation method; memetic algorithm

\section{Introduction}

The circular economy among the leading contemporary economy trends considers the environmental issues and sustainability of the business. Its definitions and concepts have differed in most research studies, including Geissdoerfer et al. [1]. Based on the relevant research studies [1-3], the circular economy is defined as a closed-loop system, in which the production resources, environmental losses, and energy leakages are minimized. Various strategies and techniques have been proposed and implemented in order to minimize the usages and losses of these resources.

The usages and productions of refurbished products are all the representative activities of circular economy. The sales of refurbished products and their relevant supply chains activities are among the most frequently applied circular economy techniques. While many research studies have provided several effective remanufacturing/refurbishing processes and techniques, most of these studies have been limited in the domain of plants and the factory planning level. This shows that more expanded agendas (e.g., the investments and strategies for gathering recycling components) have been studied less comparatively. This paper provides a new and effective production planning framework that considers additional recycling investments strategies in order to overcome these issues. While the existing strategies (e.g., additional installment of collecting facilities, special promotion for the gatherings or recycling exchange compensation) may boost the collection of more recycling components, excessive 
investments might harm the corporate or business profits. This paper considers both the collection strategies and current production constraints in tandem with the proposed integrated framework.

The proposed framework characteristics are summarized while considering more vague uncertainties and the embedded nonlinearities. While a general process planning has several uncertainties, including unclear demand and supply abilities, the circular economy-based process planning should consider the more expanded uncertainties, together with the return rates of the recycling modules. Additionally, the prediction time horizon for the return rate is not aligned with the overall production planning time horizon. It results from the fact that the gathering of the recycling modules mainly depends on the number of products sold prior. Subsequently, its gathering pattern has the typical nonstationary characteristics. Moreover, the efforts for enhancing the return rate for obtaining a considerable number of recycling modules exponentially increase. This tendency can be through nonlinear cost functions of recycling investments.

This paper integrates these characteristics when considering the economic and environmental viewpoints through stochastic programming approaches. The embedded uncertainties are captured while using time-series data analyses and the relevant probabilities. Nonlinear profit and cost structures are modelled while using fitted nonlinear functions. The integrated model is a type of stochastic nonlinear programming models. A more effective and accurate solving method is required for the proposed framework, while numerous research studies provided effective solving techniques. In order to solve the circular economy-based process planning including the assertion of gathering investments for refurbished modules, this paper provides an integrated stochastic programming framework while using Monte-Carlo's sample average approximation and the memetic algorithm. The framework is implemented for a software program supporting circular economy-based production planning, so as to prove the effectiveness and solving techniques of the proposed framework. Its effectiveness is then tested through comparisons of the results under various scenarios and analyses in this study.

The following section presents the relevant background information and literature reviews. Section 3 describes the strategic decision framework and the mathematical model supporting the circular economy. Section 4 proposes the efficient algorithms for the suggested framework. Ultimately, its effectiveness is confirmed with the implementation of the framework and its numerical analyses in Section 5 .

\section{Background and Literature Review}

Circular economy is a main stream economy concept that is being fronted by every government, municipality, and corporation, as highlighted in the previous section. Circular economy has emerged fast with cooperative movements and regulations, while similar concepts and activities have been discussed and implemented widely since 2000. Numerous research studies have defined the term Circular Economy (CE) and categorized it while using various concepts. Table 1 shows the recent $\mathrm{CE}$ concepts, keywords, and main ideas. These studies can be considered through integrations and modifications of the past former CE studies. 
Table 1. Concepts and main ideas for Circular Economy (CE).

\begin{tabular}{|c|c|c|}
\hline Research Studies & Main Concept for CE & Key Ideas for CE \\
\hline Cullen [4] & $\begin{array}{l}\text { - Conservation of the quantity } \\
\text { of materials } \\
\text { - Minimization of dissipative } \\
\text { material losses }\end{array}$ & $\begin{array}{ll}- & \text { Measurement of } \\
\text { resources' circularity } \\
\text { - } \\
\text { Recycling of a recoverable } \\
\text { end-of-life (EOL) }\end{array}$ \\
\hline Boken et al. [5] & $\begin{array}{ll}\text { - } & \text { Increasing } \\
\text { product/material's circularity }\end{array}$ & $\begin{array}{l}\text { - Challenges for exploiting } \\
\text { intuitional opportunities }\end{array}$ \\
\hline EMF [6] & $\begin{array}{l}\text { - } \quad \text { Enhancing circularity using } \\
\text { six strategies }\end{array}$ & $\begin{array}{l}\text { - } \quad \text { Categorizing types of circular } \\
\text { economy using "the } \\
\text { butterfly diagram" }\end{array}$ \\
\hline Ness and Xing [7] & $\begin{array}{l}\text { Synthesis of "closed-loop } \\
\text { activities" and "optimized uses } \\
\text { of assets" }\end{array}$ & $\begin{array}{l}\text { - Necessity of integrated } \\
\text { methodologies against } \\
\text { shortcomings of the existing } \\
\text { CE concepts }\end{array}$ \\
\hline Hollander et al. [8] & $\begin{array}{l}\text { - } \quad \text { circular product design using } \\
\text { "design for product integrity" and } \\
\text { "design for recycling" }\end{array}$ & $\begin{array}{l}\text { - Viewpoint in regards to "product } \\
\text { design" concepts }\end{array}$ \\
\hline Mendoza et al. [9] & $\begin{array}{l}\text { Integration of manufacturing and } \\
\text { product design for enhancing CE }\end{array}$ & $\begin{array}{l}\text { A new Framework of Back-casting } \\
\text { and eco-design for the circular } \\
\text { economy (BECE) }\end{array}$ \\
\hline
\end{tabular}

While several studies have discussed the concepts and definitions of the circular economy, the next phase is on how to enhance the current CE. These issues are related to the detailed activities for CE. Ellen MacArthur Foundation (EMF) [6] used as a main referencing source for many CE research studies, categorizes these activities into six phases: Reuse, Repair, Refurbishment/Remanufacturing, Repurpose, and Recycling. Although the recycling method is the broadest CE activity among them, most of existing activities are too ineffective to generate an executable production planning. "Refurbishment/Remanufacturing" is focused more as the main CE activity in this paper, since this study focuses on an executable circular economy-based production planning.

Many research studies examined production planning frameworks on the remanufacturing processes. Savaskan et al. [10] provided a price strategy for a refurbished product and Kim et al. [11] developed a strategic pricing framework for a closed loop supply chain while using the remanufacturing process. Table 2 summarizes the characteristics of the current production planning frameworks in regards to the remanufacturing processes.

However, most of the research studies ignore investments and the relevant activities that enhance the product circularity. Existing research studies examine a production planning while using already recycled products or an estimation of the amount. While the additional investments for increasing return rate for End-of-Life (EOL) part are comparatively ignored, they establish mathematical programming models within fixed ranges of the returning rates. Consequently, the subsequent uncertainties (e.g., customers' uncertainty and modeling parameters) are modeled into fuzzy logic-based mathematical programming or nonlinear programming models. As described in the previous section, the existing studies fail to incorporate efforts for enhancing products' or modules' circularity in their production planning. In this paper, these strategies are classified as "passive investment strategies for remanufacturing". The efforts or investment to enhance return rates for EOL parts are needed in order to actively enhance CE. However, the bulk of the existing papers have ignored these efforts and their economic analyses. As a result, this paper suggests an integrated framework that simultaneously considers existing production constraints and investments for the refurbished product's circularity. For this concept, the proposed framework is classified as "active investment strategies for remanufacturing". 
Table 2. Characteristics of the existing remanufacturing-based production planning frameworks.

\begin{tabular}{|c|c|}
\hline Research Studies & Characteristics \\
\hline Savaskan et al. [10] & 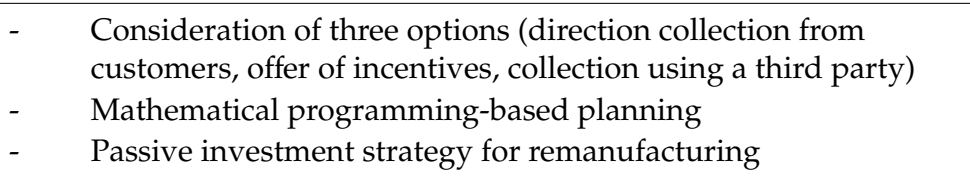 \\
\hline Kim et al. [11] & $\begin{array}{l}\text { - } \quad \text { Price based modeling framework for a closed loop supply chain } \\
\text { - } \quad \text { Fuzzy logic embedded framework } \\
\text { - } \quad \text { Passive investment strategy for "remanufacturing" }\end{array}$ \\
\hline Ghahremani-Nahr et al. [12] & $\begin{array}{l}\text { - } \quad \text { Uncertainty modeling using fuzzy logic } \\
\text { - } \quad \text { Fuzzy logic embedded mathematical programming model and } \\
\text { an usage of "Whale-optimization method" } \\
\text { - } \quad \text { Ignorance of active investment for remanufacturing }\end{array}$ \\
\hline Hashemi et al. [13] & $\begin{array}{l}\text { - } \quad \text { Aerospace remanufacturing application } \\
\text { - } \quad \text { Scenario analysis under various changes of "lead time" and } \\
\text { "defect rates" }\end{array}$ \\
\hline Pishvaee and Torabi [14] & $\begin{array}{ll}\text { - } & \text { Bi-objective probability-based mixed integer programming } \\
\text { - } & \text { Fuzzy logic-based uncertainty modeling framework } \\
\text { - } & \text { Ignorance of active investment for remanufacturing }\end{array}$ \\
\hline Turki et al. [15] & $\begin{array}{ll}- & \text { Consideration of all life cycles of a product } \\
\text { - } & \text { Genetic algorithm-based nonlinear programming model } \\
\text { - } & \text { Passive investment strategy for remanufacturing }\end{array}$ \\
\hline Shakourloo [16] & $\begin{array}{l}\text { - } \quad \text { Stochastic goal programming considering a returning rate of a } \\
\text { EOL product } \\
\text { - } \quad \text { Passive investment strategy for remanufacturing }\end{array}$ \\
\hline
\end{tabular}

The quantifying efforts for computing the circularity have been attempted by a number of research studies. Cullen [4] provided a circularity measure with (1) based on the amount of the recovered EOL material.

$$
\alpha=\frac{\text { recovered } E O L \text { material }}{\text { total production demands }}
$$

Linder et al. [17] modified (1) while using the economic values as a product-level circularity measure. However, these research studies are limited by the fact that the efforts used to increase circularity are deeply disconnected with the production planning. This paper redefines circularity and integrates it with production planning. The detailed explanations are described in the following section. Figure 1 shows several efforts and methods for increasing the circularity of the refurbishing components.

As shown in Figure 1, there are different strategies that can be applied to enhance circularity in an overall production system. The installation of additional collectors, recycling centers, distribution centers, or service centers can enhance refurbishing components' circularity. Reike et al. [18] summarized several methods for increasing the circularity. Likewise, promotions and advertisement [19] can reinforce industrial ecology. However, these methods have different Return on Investments (ROI). Additionally, it is evident that the ROI of each investment has nonlinear characteristics for achieving the target circularity. Additionally, the investment planning time horizon has to precede the production planning time. These considerations make it more difficult to effectively generate a circular economy-based production planning. 


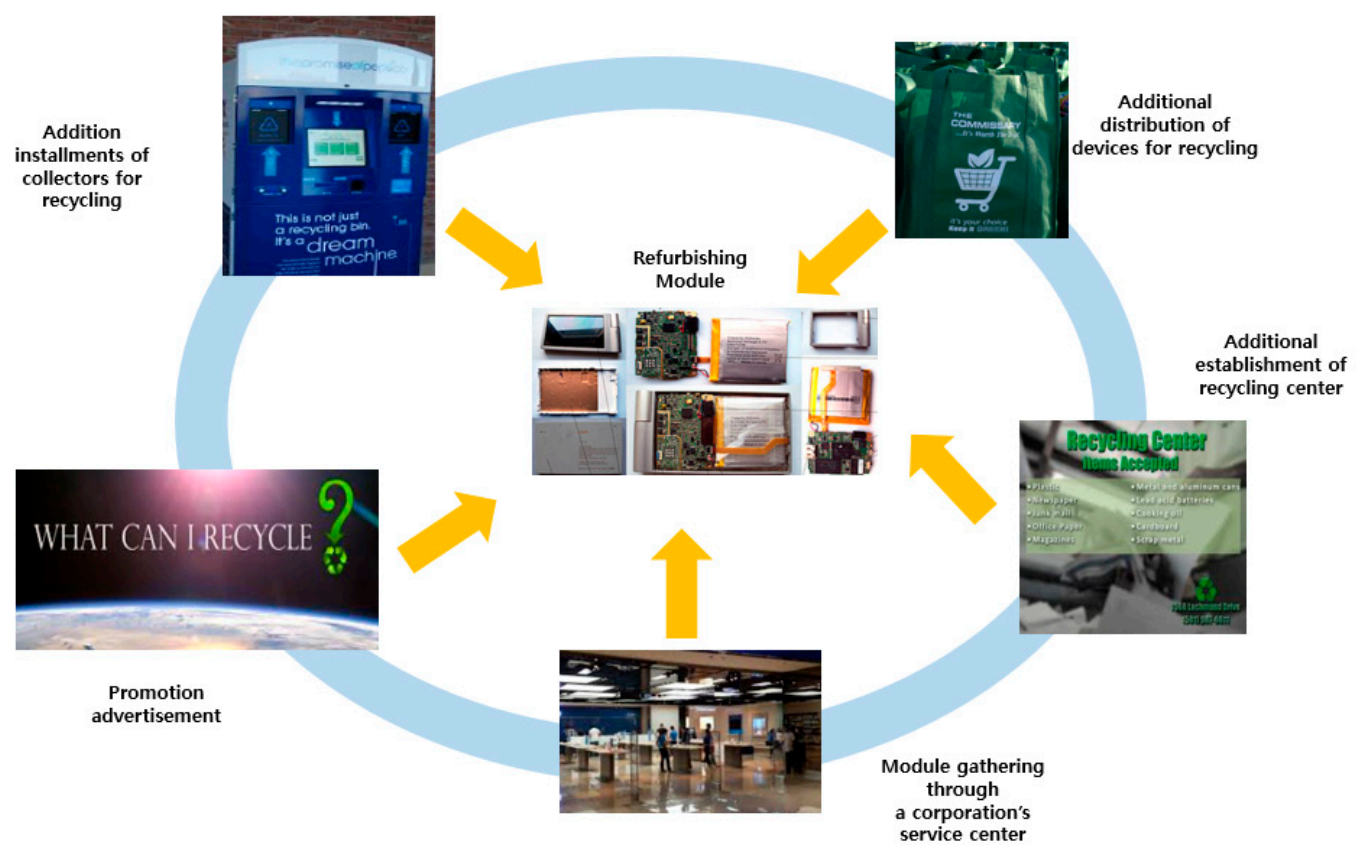

Figure 1. Methods of enhancing the circularity of the refurbishing components.

In regards to uncertainties, embedding on the circular economy is much broader when compared to those in a general production planning. The circularity rates and relevant uncertainties are entrenched more in the circular economy-based production planning while a general production planning handles several uncertainties from its demand and supply. This study simultaneously considers these uncertainties with stochastic and nonlinear characteristics.

The proposed model is based on an integrated stochastic nonlinear programming model to meet the economic and environmental planning goals. The stochastic programming model and its analyses are examined while using a number of research studies [20,21]. However, it is impossible to directly apply the existing studies' methods to the proposed framework, since the model in consideration has several demerits: information uncertainty, disparities in planning/investment time horizon, and nonlinear price characteristics. As a result, the following section provides a new and effective framework for maximizing corporate profits that simultaneously meets the criteria of high circularity.

\section{Strategic Decision Framework and Its Mathematical Model Supporting Circular Economy}

This section describes the overall proposed strategic decision framework for supporting circular economy. The targeted refurbished product is manufactured while using various components including: new parts, remanufactured parts, reused parts, and recycled parts. Figure 2 shows an example of a Bill of Material (BOM) for a refurbished product.

As shown in Figure 2, the refurbished product is manufactured and assembled while using various types of components, coupled with a variety of remanufacturing methods. This study also investigates the effective proportions of newly manufactured components and recycled components. The effective proportions of manufacturing components that were based on this research indicate that an efficient manufacturing BOM comprise of subcomponents with less production costs that meet the customers' needs. This paper is distinguished from other studies due to the consideration of gathering strategies while there are numerous related research studies on remanufacturing and recycling economy: extended advertisement, and additional installation of collecting facilities and incentive policies, as illustrated in Figure 1. While other studies only focus on the effective use of the already returned components, this paper considers the potential cost of returning components while using these investments. More collection may be achieved if these investments are effective, hence 
contributing more to circular economy. For this reason, the proposed framework is considered to be a more active strategy to support circular economy.

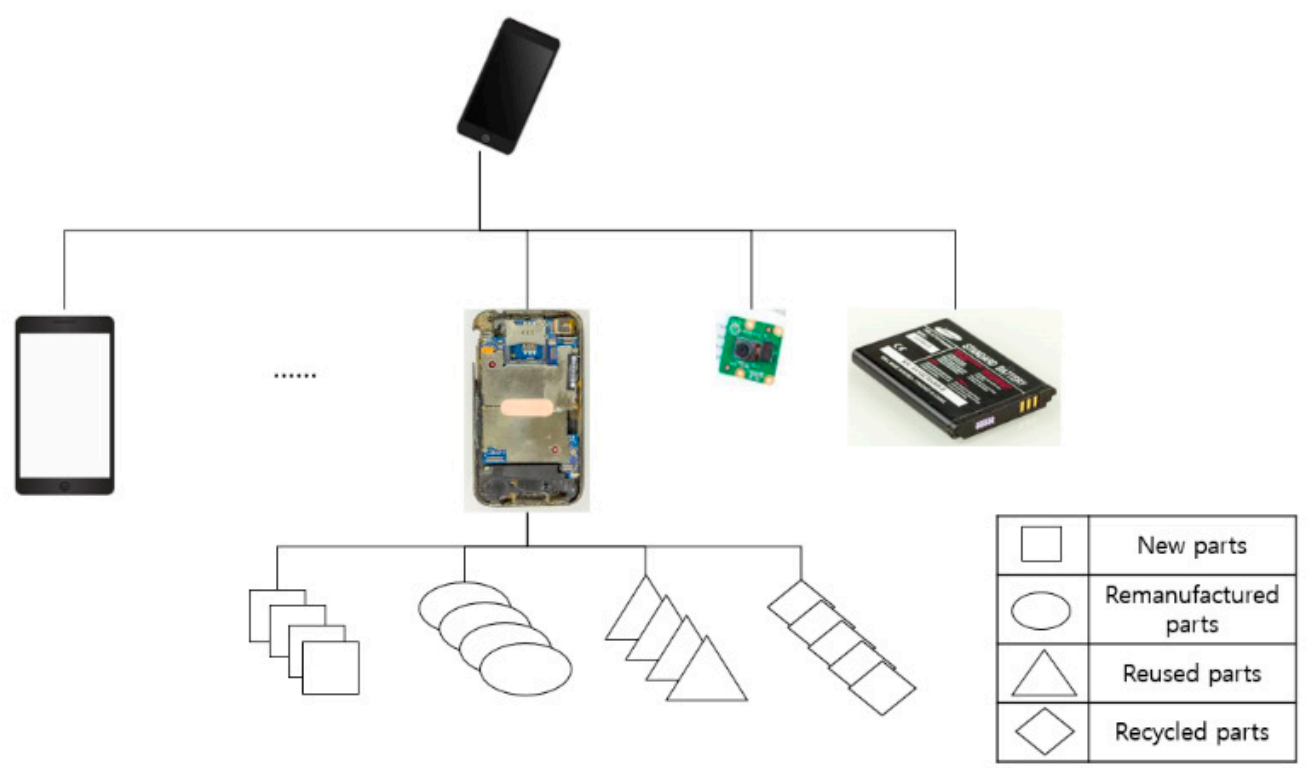

Figure 2. An example of a Bill of Material (BOM) for a refurbished product comprising of various subcomponents.

A refurbished product is comprised of several components or modules. A module is a newly manufactured part $\left(\mathrm{x}_{i}^{\mathrm{I}, \mathrm{t}}\right)$ or a refurbished component $\left(\mathrm{x}_{i, j, k}^{\mathrm{II}, \mathrm{t}}\right)$. Table 3 represents the descriptions of the detailed variables and parameters.

Table 3. Descriptions of decision variables and parameters.

\begin{tabular}{|c|c|c|c|}
\hline Symbol & Description & Units & $\begin{array}{l}\text { Decision Variable } \\
\text { (d.v.)/Parameter (p) }\end{array}$ \\
\hline $\mathrm{x}_{i}^{\mathrm{I}, \mathrm{t}}$ & $\begin{array}{l}\text { The ith Components comprising of new } \\
\text { part (I) in time period } t\end{array}$ & EA & d.v. \\
\hline$x_{i, j, k}^{I I, t}$ & $\begin{array}{l}\text { The ith Components with recycled parts (II) } \\
\text { using "remanufacturing }(j=1) \text { or reusing } \\
(j=2) \text { or recycling }(j=3) \text { " method which is } \\
\text { acquired from the kth investment. }\end{array}$ & EA & d.v. \\
\hline $\mathrm{CM}_{i}^{\mathrm{I}, \mathrm{t}}$ & Manufacturing cost per each $x_{i}^{\mathrm{I}, \mathrm{t}}$ unit & Unit cost & $\mathrm{p}$ \\
\hline $\mathrm{CR}_{i, j, k}^{\mathrm{II}, \mathrm{t}}$ & Refurbishing cost per each $x_{i, j, k}^{\mathrm{II}, \mathrm{t}}$ unit & Unit cost & $\mathrm{p}$ \\
\hline $\mathrm{R}_{i, j, k}^{\mathrm{II}, \mathrm{t}}$ & $\begin{array}{l}\text { The returned ith component with the } j \text { th } \\
\text { remanufacturing method which is acquired } \\
\text { from the kth investment at time period } t\end{array}$ & EA & - \\
\hline $\mathrm{D}^{\mathrm{t}}$ & The total demand of the product at time $t$. & EA & $\mathrm{p}$ \\
\hline $\mathrm{B}_{\mathrm{i}}$ & $\begin{array}{l}\text { The number of the } i \text { th component in a } \\
\text { product }\end{array}$ & EA & $\mathrm{P}$ \\
\hline$\tau_{k}^{\mathrm{t}}$ & $\begin{array}{l}\text { The return rate of a product using the } k t h \\
\text { method at time } t\end{array}$ & $\tau_{k}^{\mathrm{t}} \in[0,1]$ & d.v. \\
\hline $\mathrm{P}^{\mathrm{II}}$ & The price of a refurbished product & Unit cost & $\mathrm{p}$ \\
\hline $\mathrm{Cl}_{\mathrm{k}}$ & $\begin{array}{l}\text { Investment cost for the } k t h \text { method for } \\
\text { increasing returning rate }\end{array}$ & Unit cost & $\mathrm{p}$ \\
\hline
\end{tabular}


Each component has a manufacturing cost per a unit $\left(\mathrm{CM}_{j}^{\mathrm{I}, \mathrm{t}}\right.$ or $\left.\mathrm{CR}_{i, j, k}^{\mathrm{II}, \mathrm{t}}\right)$ in regards to its manufacturing types, respectively. While a completely new product only comprises of each $x_{i}^{\mathrm{I}, \mathrm{t}}$, a refurbished product comprises of several $x_{i}^{\mathrm{I}, \mathrm{t}, \mathrm{s}} \mathrm{s}$ and $x_{i, j, k}^{\mathrm{II}, \mathrm{t}} \mathrm{s}$. The required number of the $i$ th module is represented as $B_{i}$ in a product. When $D^{t}$ is the customer's demand for a refurbished product at time $t$, the number of collected components $\left(\mathrm{R}_{i, j, k}^{\mathrm{II}, \mathrm{t}}\right)$ has to be considered. (2) denotes the constraints for meeting $\mathrm{D}^{\mathrm{t}}$.

$$
\mathrm{x}_{i}^{\mathrm{I}, \mathrm{t}}+\sum_{j} \sum_{k} x_{i, j, k}^{\mathrm{II}, T} \geq D^{t} \cdot B_{i}, \mathrm{i} \in \mathrm{M}
$$

The returned amount $\mathrm{R}_{i, j, k}^{\mathrm{II}, \mathrm{t}}$ depends on the return rate $\tau_{k}^{\mathrm{t}}$. (3) denotes the relationship between $\mathrm{R}_{i, j, k}^{\mathrm{II}, \mathrm{t}}$ and $\tau_{k}^{\mathrm{t}}$.

$$
\mathrm{R}_{i, j, k}^{\mathrm{II}, \mathrm{t}}=D^{t-\Delta t} \cdot \tau_{k}^{t-\Delta t} \cdot B_{i}
$$

The usage of " $t-\Delta t$ " denotes that the reused/remanufactured/recycled components are collected at time $\mathrm{t}-\Delta \mathrm{t}$ before meeting customers' demand at time $\mathrm{t}$. As shown in Equation (3), it is reasonable that $\mathrm{R}_{i, j, k}^{\mathrm{II}, \mathrm{t}}$ at time $t$ is collected not from current customers' demand $D^{t}$, but from the previous consumed amount $\mathrm{D}^{\mathrm{t}-\Delta \mathrm{t}}$. In this manner, $\Delta \mathrm{t}$ is interpreted as the returning time horizon of a products. Subsequently, (4) denotes the relationship between $x_{i, j, k}^{\mathrm{II}, \mathrm{t}}$ and $\mathrm{R}_{i, j, k}^{\mathrm{II}, \mathrm{t}}$.

$$
\mathrm{x}_{i, j, k}^{\mathrm{II}, \mathrm{t}} \leq \mathrm{R}_{i, j, k}^{\mathrm{II}, \mathrm{t}}
$$

In general, a factory tends to produce the product using the refurbished or reused part with the constraint, $\mathrm{CM}_{i}^{\mathrm{I}, \mathrm{t}} \geq \mathrm{CR}_{i, j, k}^{\mathrm{II}, \mathrm{t}}$ if recycling parts exist. However, returned parts may be insufficient for meeting $\mathrm{D}^{\mathrm{t}}\left(\mathrm{D}^{\mathrm{t}} \cdot B_{i}>\mathrm{R}_{i, j, k}^{\mathrm{II}, \mathrm{t}}\right)$ in a general situation. While existing production plans attempt to use its new part in the situation, this study considers another alternative plan-efforts in enhancement of the return rates at planning time $\mathrm{t}-\Delta \mathrm{t}$.

The investment cost $\left(\mathrm{Cl}_{\mathrm{k}}\right)$ is additionally needed when the $k t h$ investment is determined while using an effective strategy. In general, $\mathrm{Cl}_{\mathrm{k}}$ is represented while using a nonlinear function of $\tau_{k}^{\mathrm{t}}$ in (5).

$$
\mathrm{Cl}_{\mathrm{k}}=g\left(\tau_{k}^{t}\right)
$$

where $\mathrm{g}(\cdot)$ is a nonlinear function

However, these investments consider additional efforts for collecting refurbishing products. It means that a certain constant amount at time $t$ can be collected without additional efforts. (6) denotes this situation.

$$
\tau_{k}^{t-\Delta t}=\hat{\tau}_{k}^{t-\Delta}+\alpha_{k}^{t-\Delta t}
$$

The estimation of $\hat{\tau}_{k}^{t-\Delta}$ can be achieved by a number of statistical methods (e.g., time series analysis and other data mining methods) with the previous historical data. Section 4 provides the detailed estimation and analyses. Subsequently, (5) is substituted by (7) in this manner.

$$
\mathrm{Cl}_{\mathrm{k}}=f\left(\alpha_{k}^{t}\right)
$$

Figure 3 shows an example of a nonlinear function explaining the relationship between $\mathrm{Cl}_{\mathrm{k}}$ and $\alpha_{k}^{t}$. As shown in Figure 3, each $\mathrm{k}$ means an index that represents each investment (1: advertisement, 2: additional installment of collecting facilities, and 3: incentive policy). 


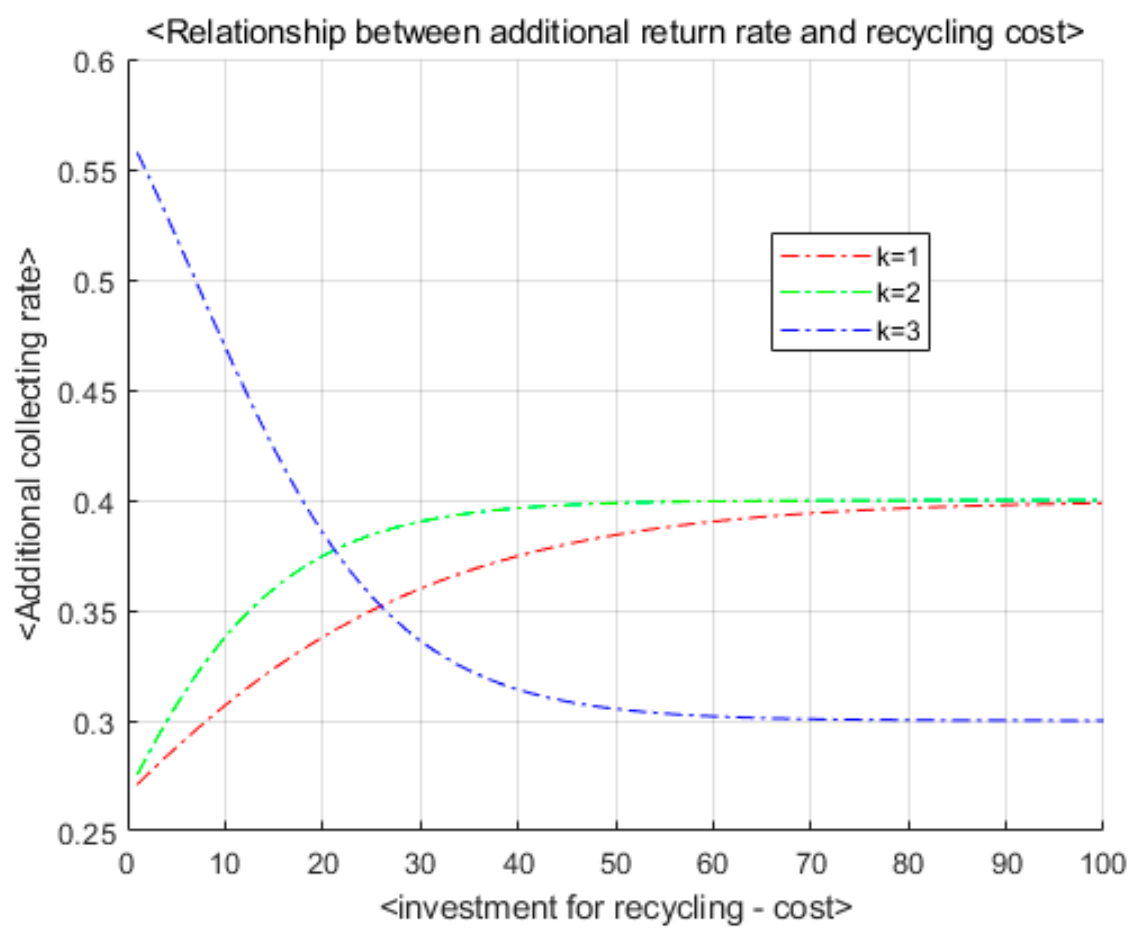

Figure 3. An example of a nonlinear function between $\mathrm{Cl}_{\mathrm{k}}$ and $\tau_{k}^{\mathrm{t}}$.

This research focuses on the effective gathering investment strategy while considering the existing returned volume, the predicted return rates, and an estimated demand. The demand $\left(\mathrm{D}^{t}\right)$ is determined while using previous market data and forecasts. Since various uncertainties are embedded in its prediction, it is only rational that the demand be represented while using a probability density function. Figure 4 shows the estimated $\mathrm{D}^{\mathrm{t}}$ that is represented using a probability distribution.

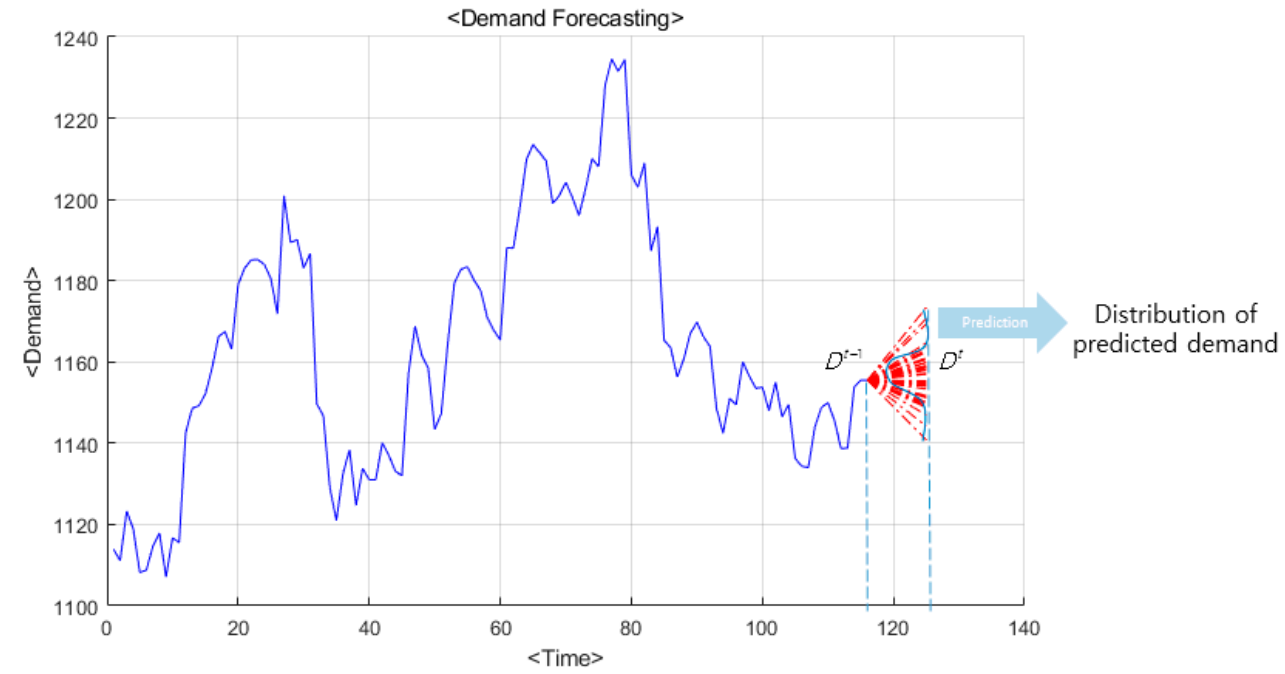

Figure 4. Estimation of $D^{t}$ using a probability distribution. 
The Formulas (2)-(7) are used as constraints in determining the effective manufacturing strategy for a refurbished product. The objective (8) of the decision at time $t$ is to maximize the profit while considering the difference in price of the product and the overall production cost.

$$
\max \left[P^{I I} \cdot D^{t}-\sum_{i=1}^{m}\left(C M_{i}^{I, t} \cdot x_{i}^{I, t}+\sum_{j}^{n} \sum_{k}^{o} C R_{i, j, k}^{I I, t} \cdot x_{i, j, k}^{I I, t}\right)-\sum_{j=1}^{m} C l_{k} \cdot D^{t-\Delta t} \cdot \alpha_{k}^{t-\Delta t}\right]
$$

The mathematical programming model provided is categorized as a stochastic nonlinear programming model. The model has the characteristics of a stochastic programming model since $\mathrm{D}^{t}$ is represented while using a probability distribution. Additionally, the model has nonlinear terms from (7) and (8). Consequently, several parameters that are embedded in the model have to be estimated through statistical analyses. Figure 5 illustrates the overall procedures for the proposed effective production planning.

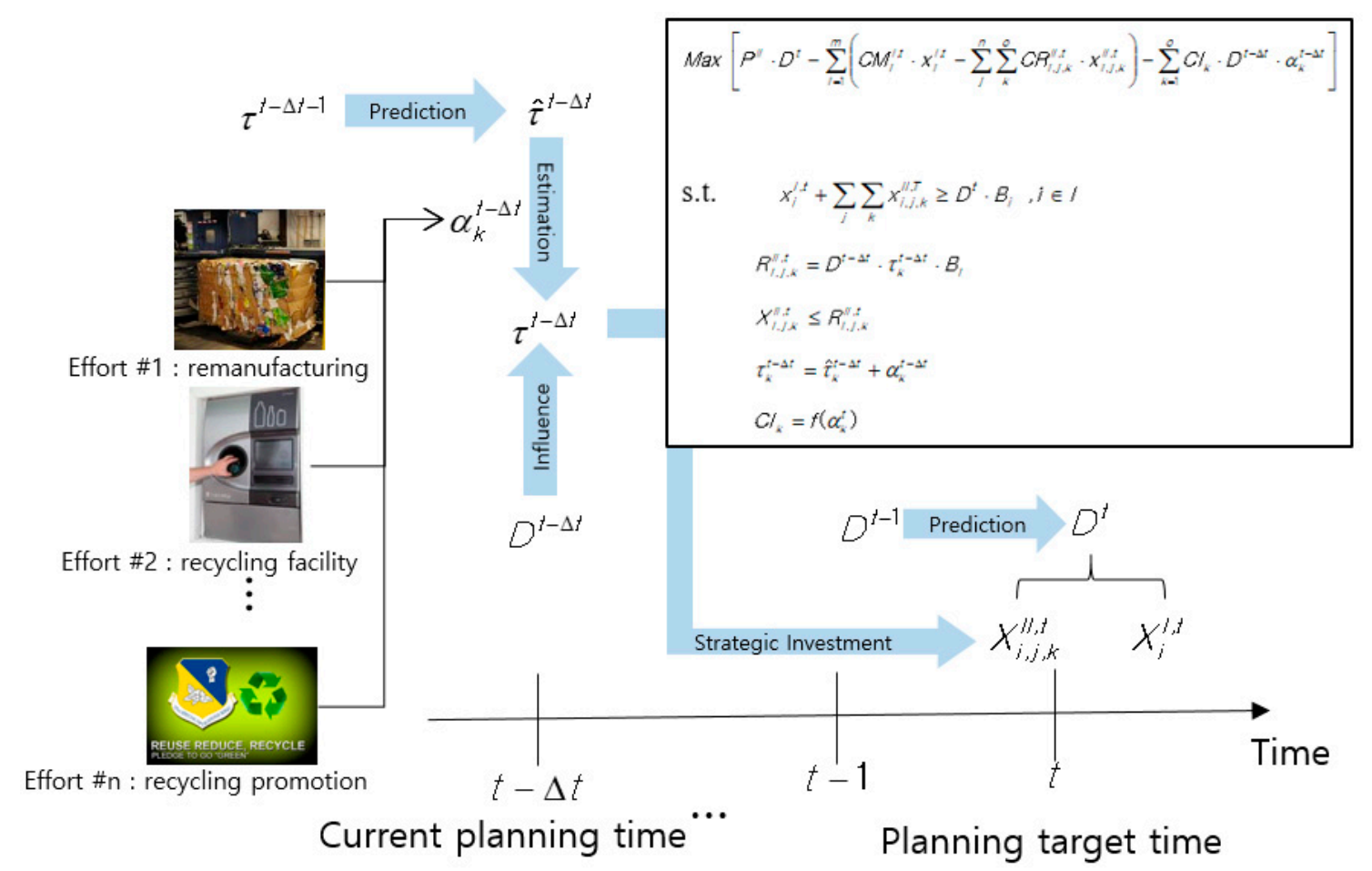

Figure 5. Overall procedure of the proposed framework.

The following section illustrates the detailed methodologies that are applied in solving the proposed model.

\section{Parameter Estimation and Analysis Using Stochastic Nonlinear Optimization}

As highlighted in the previous section, the proposed mathematical model shares the characteristics of a stochastic nonlinear programming. Moreover, statistical analyses have to be satisfied in advance as the prerequisite determinations for estimating the parameters $D^{t}$ and $\hat{\tau}_{k}^{t-\Delta}$. This study uses a time-series based method to approximate the model parameters.

Figure 6 shows a flow diagram for implementing the proposed circular economy-based process planning. The accurately predicted demand $\left(D^{t}\right)$ and the collecting volume $\left(\hat{\tau}_{k}^{t-\Delta}\right)$ heavily influence on the solutions and analyses of the proposed model. The estimations of $D^{t}$ and $\hat{\tau}_{k}^{t-\Delta}$ are estimated while using the current manufacturing plans and data, and are mainly driven using a time series technique. This research utilizes Autoregressive Integrated Moving Average (ARIMA) method or other nonlinear prediction methods for covering nonstationary data. The analyses of many research studies [22-24] 
assumes that most of the production demands and manufacturing related tendencies follow the nonstationary stochastic characteristics. Although $\hat{\tau}_{k}^{t-\Delta}$ can be monitored or directly estimated while using one of those methods, $\mathrm{D}^{t}$ is predicted using several existing time-series methods that enhance the accuracy of these estimations. These values are then represented while using a random variable $\xi$ following a Gaussian distribution $\mathrm{N}\left(\mu, \sigma^{2}\right)$. Both parameters $\mu$ and $\sigma$ are estimated while using the predicted results from several time-series methods. Instead of the single value-based prediction, the application of this probability distribution enhances the representation power of the estimated demand. $\mathrm{D}^{t}$ can then be replaced with (9) while using a stochastic programming through recourse model with the bounds.

$$
\mathrm{D}^{\mathrm{t}} \Rightarrow E[\min (q, \xi)]
$$

where $\mathrm{q}=\min \left(\frac{x_{i}^{I, t}+\sum_{j} \sum_{k} X_{i, j, k}^{I I, t}}{B_{i}}, \mathrm{i} \in \mathrm{M}\right)$.

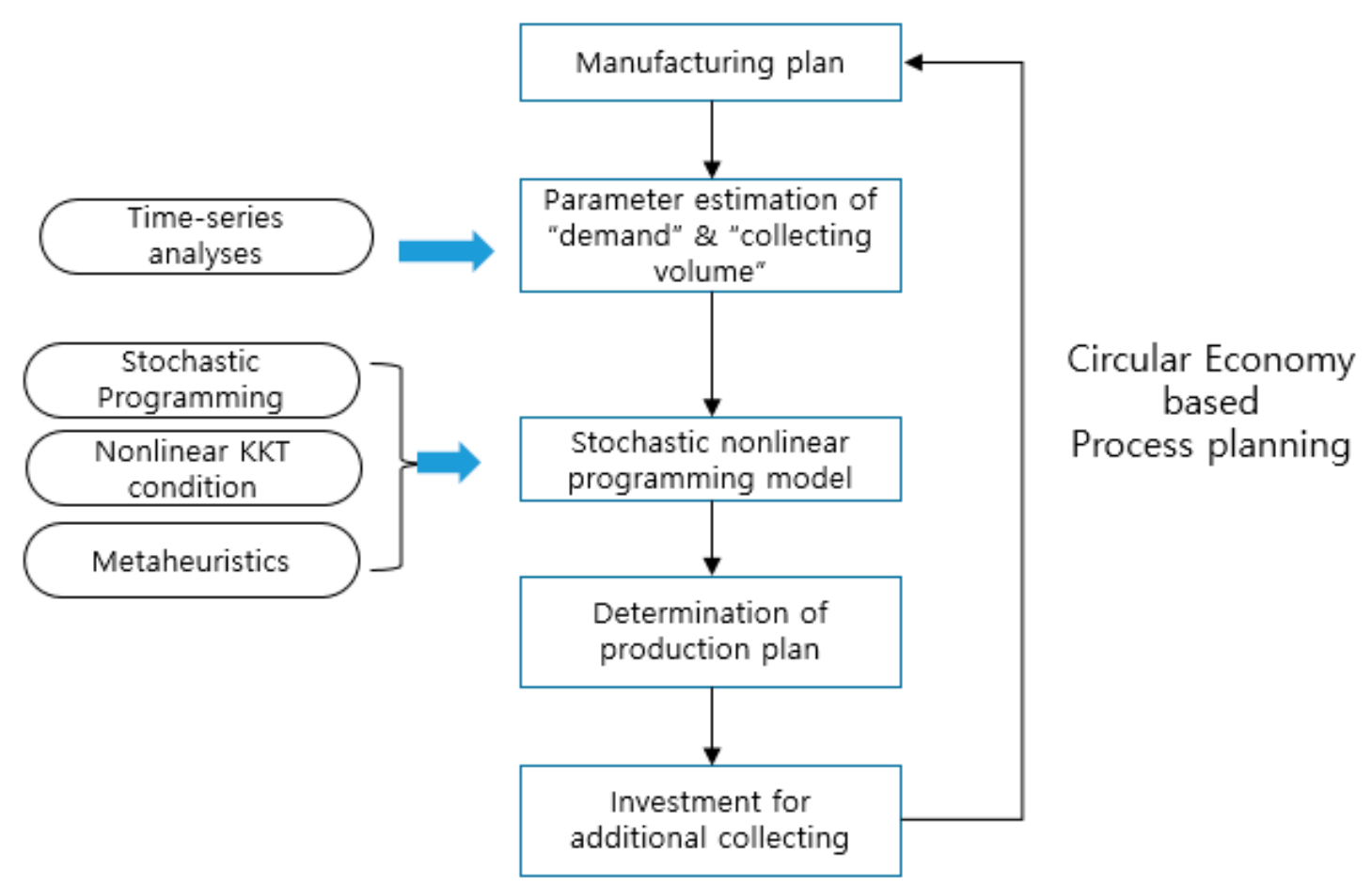

Figure 6. Flow diagram for implementing the proposed circular economy-based process planning.

As shown in the objective function (10), the mathematical model is categorized as a two-stage stochastic programming with the recourse model.

$$
\max \left[P^{I I} \cdot E[\min (q, \xi)]-\sum_{i=1}^{m}\left(C M_{i}^{I, t} \cdot x_{i}^{I, t}+\sum_{j}^{n} \sum_{k}^{o} C R_{i, j, k}^{I I, t} \cdot x_{i, j, k}^{I I, t}\right)-\sum_{k=1}^{o} f\left(\alpha_{k}^{t-\Delta t}\right) \cdot D^{t-\Delta t} \cdot \alpha_{k}^{t-\Delta t}\right]
$$

In the case that a nonlinearity condition (7) is excluded, a general method of applying the stochastic transformations and KKT conditions [20] can be used, owing to its near-optimal solution. However, the existence of the provided conditions results in the difficulties in determining the global minimum from the recourse model. In order to overcome this discrepancy, many research of the studies, including Sakalauskas [25] and Shapiro [26], provided the Monte-Carlo based stochastic nonlinear programming solving-Sample averaging approximation (SAA) method. This paper applies the SAA method to generate more effective solutions. However, the solutions that were obtained using SAA method [27] 
are compared with different criteria, such as unbiasedness, consistency, and convergence. According to Shapiro [28], (9) can be replaced with (11), where $p_{i}$ is the probability for ith scenario.

$$
\mathrm{E}[\min (\mathrm{q}, \xi)]=\sum_{i=1}^{k} \min \left(q, \xi_{i}\right) \cdot p_{i}
$$

where $\xi_{\mathrm{i}}$ is the $\mathrm{i}$ th sample from $\mathrm{N}\left(\mu, \sigma^{2}\right)$

Subsequently, (12) is driven by the Law of Large Numbers [29].

$$
\frac{\sum_{i=1}^{N} \min \left(q, \xi_{i}\right)}{N} \rightarrow \mathrm{E}[\min (\mathrm{q}, \xi)] \text { w.p. } 1
$$

It can be easily ascertained that the estimator $\frac{\sum_{i=1}^{N} \min \left(q, \xi_{i}\right)}{N}$ is the unbiased and consistent estimator of $\mathrm{E}[\min (\mathrm{q}, \xi)]$, as each $\xi_{\mathrm{i}}$ is an i.i.d. sample and driven from Gaussian distribution $\mathrm{N}\left(\mu, \sigma^{2}\right)$. The sample size $\mathrm{N}$ is determined while using the empirical test following the criteria (13) In order to support the convergence condition of the estimator, where $\epsilon, \alpha$, and $\delta$ are the parameters from Kleywegty et al. [30].

$$
\mathrm{N} \geq \frac{3 \sigma^{2}}{(\epsilon-\delta)^{2}} \ln \left(\frac{\xi}{\alpha}\right)
$$

(12) and (13) make it possible to solve the proposed model while using the Monte-Carlo based SAA method. The remaining issues include the handling of the nonlinear conditions and the terms resulting from (7). These issues can be addressed while using memetic based metaheuristics [31]. The memetic algorithm $[32,33]$ is a type of metaheuristics method that combines the current metaheuristics and local searching techniques. While metaheuristic algorithms attempt to discover more solutions that are more improved when compared to the current local optimum, they are limited in regards to their searching efficiencies, such as solution accuracy and convergence. In general, the obtained quality of a local solution using metaheuristics is less than the quality that was obtained while using the heuristics method with the same input range. The local optimum searching method is combined with a metaheuristic algorithm in order to overcome these limitations. In a memetic algorithm, an alternative solution is realized while using an optimization method. It guarantees the quality of the calculated local solution within its local range. Consequently, the local solution is morphed into a better solution while using a metaheuristic. Neri and Cotta [34] summarized the existing literatures using memetic algorithms. Numerous applications and research studies, including the one by Neri and Cotta [34], use several memetic algorithms that combine various local search methods and metaheuristics to find finding more efficient parameters or solutions. This paper applies a memetic method for finding more efficient investment strategies, which supports circular economy. The applied memetic method utilizes a gradient searching technique in place of the local searching and a Genetic Algorithm as a metaheuristics method. Choo and Lee [35] applies the similar memetic learning framework to determine the parameters in a deep learning machine.

As a local searching method, this study uses a KKT based gradient method. Each constraint ((2)-(6)) is combined to (10) with each Lagrange multiplier. Subsequently, each decision variable's update is achieved while using the driven Lagrange function $\mathrm{L}\left(\mathrm{x}_{i}^{\mathrm{I}, \mathrm{t}}, \mathrm{x}_{i, j, k^{\prime}}^{\mathrm{II}, \mathrm{t}} \alpha_{k}^{\mathrm{t}-\Delta \mathrm{t}}\right)_{i \in M, j \in J, k \in K}$ and each differential $\frac{\partial}{\partial \phi} L\left(\mathrm{x}_{i}^{\mathrm{I}, \mathrm{t}}, \mathrm{x}_{i, j, k^{\prime}}^{\mathrm{II}, \mathrm{t}} \alpha_{k}^{\mathrm{t}-\Delta \mathrm{t}}\right)$, where $\phi$ is a decision variable.

$$
\mathrm{x}_{i}^{\mathrm{I}, \mathrm{t}^{\prime}} \leftarrow \mathrm{x}_{i}^{\mathrm{I}, \mathrm{t}}+\eta \cdot\left(\frac{1}{B_{i}}-C M_{i}^{\mathrm{I}, \mathrm{t}}+\lambda_{(1)}^{i}\right)
$$

where $\lambda_{(1)}^{i}=$ a Lagrange multiplier for the constraint type (2). 
and, $\eta=$ a step length

$$
\mathrm{x}_{i, j, k}^{\mathrm{II}, \mathrm{t}^{\prime}} \leftarrow \mathrm{x}_{i, j, k}^{\mathrm{II}, \mathrm{t}}+\eta \cdot\left(\frac{1}{B_{i}}-C M_{i, j, k}^{\mathrm{II}, t}+\lambda_{(1)}^{i}\right)
$$

(14) and (15) denotes the learning procedures for each production and returning component, respectively. Similarly, (16) denotes how each investing strategy is learned for the more effective circular economy.

$$
\alpha_{k}^{\mathrm{t}-\Delta \mathrm{t}^{\prime}} \leftarrow \alpha_{k}^{\mathrm{t}-\Delta \mathrm{t}}+\eta_{\alpha} \cdot\left(\lambda_{(5)}^{k} \frac{1}{B_{i}}-\frac{\partial f\left(\alpha_{k}^{\mathrm{t}-\Delta \mathrm{t}}\right)}{\partial \alpha_{k}^{\mathrm{t}-\Delta \mathrm{t}}} \cdot C I_{k} \cdot D^{t-\Delta t}\right)
$$

The usages of different step sizes $\left(\eta\right.$ and $\eta_{\alpha}$ ) result from the different resolutions of the decision variables $\mathrm{x}_{i}^{\mathrm{I}, \mathrm{t}}, \mathrm{x}_{i, j, k^{\prime}}^{\mathrm{II}, \mathrm{t}}$ and $\alpha_{k}^{\mathrm{t}-\Delta \mathrm{t}}$. The more improved solution is attempted using the Genetic algorithm (GA) when a local optimum is arrived using (14), (15), and (16). The genotype conversion is achieved using the binary number conversion from a decimal number. For instance, an initial value of a decision variable $x_{i, j, k}^{\mathrm{II}, \mathrm{t}}$ is obtained while using (17) and a randomly generated number $\mathrm{r}$.

$$
\mathrm{x}_{i, j, k}^{\mathrm{II}, \mathrm{t}} \leftarrow \mathrm{r} \cdot\left(\frac{D_{t}}{B_{i}}-x_{i}^{I, t}-\sum_{l}^{N} \sum_{m}^{o} x_{i, l, m, l \neq j, m \neq k}^{I I, t}\right)
$$

The generated decimal value is converted into the corresponding binary value. Afterwards, crossover is achieved while using Single-point crossover [36]. The mutation is achieved with a conversion $(0 \rightarrow 1$ or $1 \rightarrow 0$ ) of its binary value in a randomly determined position. This position is determined using (18), where $B(n)$ is the binary representation of the decimal value $n$ and $d(n)$ is the digit number of $n$.

$$
\left\lfloor d\left(B\left(\frac{D_{t}}{B_{i}}-x_{i}^{I, t}-\sum_{l}^{N} \sum_{m}^{o} x_{i, l, m, l \neq j, m \neq k}^{I I, t}\right)\right) \cdot r\right\rfloor
$$

where $\lfloor n\rfloor=$ the rounded-off value of $\mathrm{n}$.

Table 4 shows the applied Genetic algorithm procedure in this research. The provided algorithm has four parameters: $t h, p, r$, and $m$. th is a threshold value specifying the termination criterion of the algorithm. $p$ is the number of the tested solutions in each GA iteration. $r$ is the fraction of the solution set that is to be replaced by the crossover operation and $m$ indicates the mutation rate.

Table 4. The applied Genetic Algorithm.

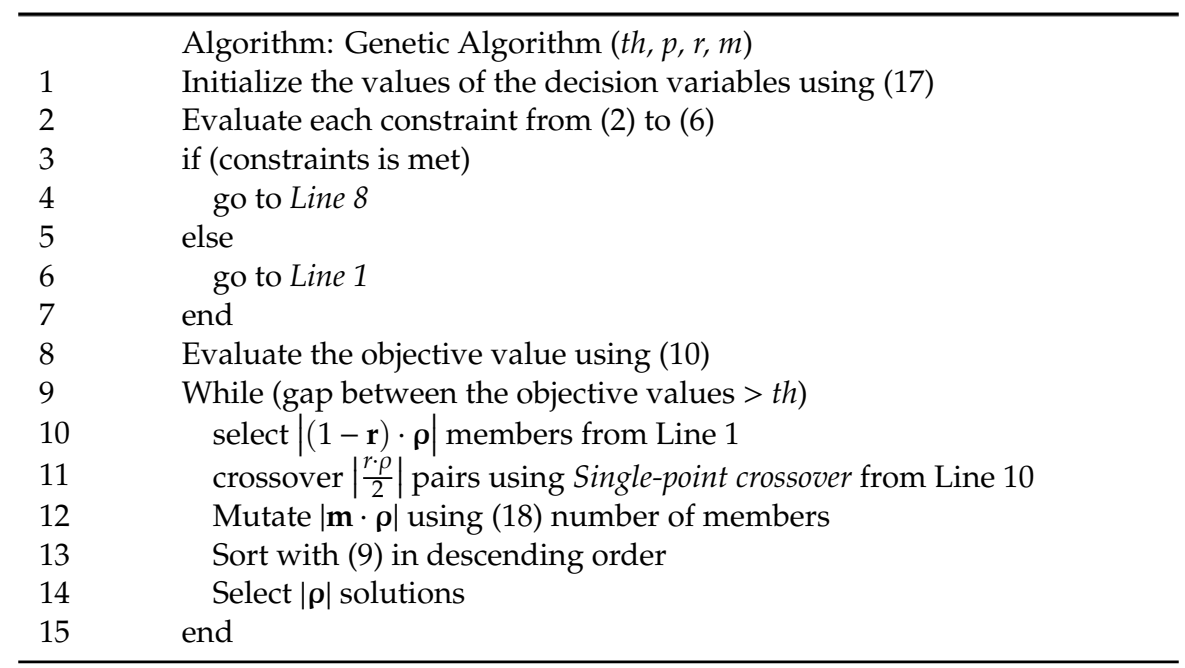


The overall solution procedure for the proposed model combines the Genetic algorithm that is shown in Table 4 with the gradient based local searching provided in (14), (15), and (16). During these processes, $E[\min (q, \xi)]$ is projected while using the sample averaging approximation method. The mathematical model provided and the stochastic nonlinear programing based method contributes to the estimation of effective collecting strategies. As the reputation of circular economy grows more and more, production/collection quantities and related BOM portions become crucial decision factors. The relevant collecting investments, together with their budget strategies, have to be considered in this model. The proposed framework is considered as an effective remanufacturing in support of the circular economy. The ensuing section describes the developed remanufacturing systems and its numerical studies' analyses.

\section{Development of Remanufacturing Framework and Its Numerical Analysis}

This section describes the implementation of the proposed framework and the numerical analyses while using the proposed software program. The system includes several information/parameter panels and three graph windows. Table 5 represents the roles and functions of each panel/windows.

Table 5. Roles and functions of each panel and window.

\begin{tabular}{|c|c|c|c|}
\hline Type & Roles & Organization & Functions \\
\hline Window & $\begin{array}{l}\text { Demand } \\
\text { forecasting }\end{array}$ & Demand plot & $\begin{array}{ll}\text { - } & \text { Plotting the demand data } \\
\text { - } & \text { Analyzing data } \\
\text { - } & \text { Output: Gaussian dist.-based } \\
& \text { predicting demand }\end{array}$ \\
\hline Window & $\begin{array}{l}\text { Return rate } \\
\text { estimation }\end{array}$ & Plot of existing Return rate & $\begin{array}{ll}\text { - } & \text { Monitoring return rate } \\
\text { - } & \text { Capturing return rate for circular } \\
\text { economy-based } \\
\text { production planning }\end{array}$ \\
\hline Panel & Main information & $\begin{array}{ll}- & \text { Number of } \\
\text { BOM components } \\
-\quad \\
B_{i}\end{array}$ & $\begin{array}{ll}- & \text { Specifying BOM and } \\
\text { related information } \\
\text { - } & \text { Editing with the real data }\end{array}$ \\
\hline Panel & $\begin{array}{l}\text { Price information } \\
\text { Setting }\end{array}$ & $\begin{array}{ll}\text { - } & \text { Price of a refurbish product } \\
\text { - } & \text { newly manufacturing cost } \\
\text { per module } \\
\text { - } & \text { recycling cost per module }\end{array}$ & $\begin{array}{ll}\text { - } & \text { Specifying price information } \\
\text { - } & \text { Editing with the real price data }\end{array}$ \\
\hline Panel & $\begin{array}{l}\text { Investment strategy } \\
\text { information }\end{array}$ & $\begin{array}{l}\text { number of investment } \\
\text { strategies for } \\
\text { circular economy } \\
\text { each investment } \\
\text { cost/product }\end{array}$ & $\begin{array}{ll}\text { - } & \text { Specifying information for } \\
\text { investment strategies } \\
\text { - } \quad \text { Nonlinear equations can be } \\
\text { embedded in the system } \\
\text { - } \quad \text { Editing with user data }\end{array}$ \\
\hline Panel & $\begin{array}{l}\text { Memetic algorithm } \\
\text { parameters }\end{array}$ & $\begin{array}{l}\text { - } \quad \text { Parameters for local search } \\
\text { - } \quad \text { Parameters } \\
\text { for metaheuristics }\end{array}$ & $\begin{array}{l}\text { - } \quad \text { Setting parameters for the } \\
\text { gradient descent search methods } \\
\text { - Setting parameters for } \\
\text { Genetic algorithm }\end{array}$ \\
\hline Window & Solution & $\begin{array}{ll}\text { - } & \text { plots of objective } \\
\text { function values }\end{array}$ & $\begin{array}{l}\text { - } \quad \begin{array}{l}\text { Showing trends of the } \\
\text { objective function }\end{array}\end{array}$ \\
\hline
\end{tabular}

Table 6 shows an analyzed numerical example to illustrate the effectiveness of the proposed framework. 
Table 6. Data and Parameters for a case study and its analyses.

\begin{tabular}{lll}
\hline Type & \multicolumn{2}{l}{ Values } \\
\hline & - & Number of BOM modules: 6 \\
& - & $\mathrm{B}_{\mathrm{i}}=[2,1,1,1,2,1]$ \\
Input & - & $\mathrm{CM}_{i}^{\mathrm{I}, \mathrm{t}}=[250,500,1750,2000,2250,1750]$ \\
& - & $\mathrm{CR}_{i, j, k}^{\mathrm{II}, \mathrm{t}}=[0,0,600,500,500,450,0,0,600,500,500,450,0,0,600$, \\
& & $500,500,450,0,0,600,500,500,450]$ \\
& - & $\mathrm{Cl}_{\mathrm{k}}=[214389357429]$ \\
& - & $\tau_{k}^{\mathrm{t}}=0.4 /-\mathrm{D}^{\mathrm{t}-\Delta \mathrm{t}}=8450$ \\
\hline \multirow{3}{*}{ Parameters } & - & Local search iteration number: 10,000 \\
& - & $\eta=0.01 /-\eta_{-} \alpha=0.110$ \\
& - & $t h=0.0001 /-p=10 /-r=1 / 6 /-m=0.2$ \\
\hline \multirow{3}{*}{ Initial solutions } & - & $\mathrm{x}_{i}^{\mathrm{I}, \mathrm{t}}=[0,0,0,0,0,0]$ \\
& - & $\mathrm{x}_{i, j, k}^{\mathrm{II}, \mathrm{t}}=[0,0,0,0,0,0,0,0,0,0,0,0,0,0,0,0,0,0,0,0,0,0,0,0]$ \\
& & $\alpha_{k}^{\mathrm{t}-\Delta \mathrm{t}}=[1,1,1,1]$ \\
\hline
\end{tabular}

The current return rate data and historical demand data in the customized formats are read in the system after inputting the initial solutions and parameters in the developed system. These data is then plotted and analyzed, as shown in Figure 7.
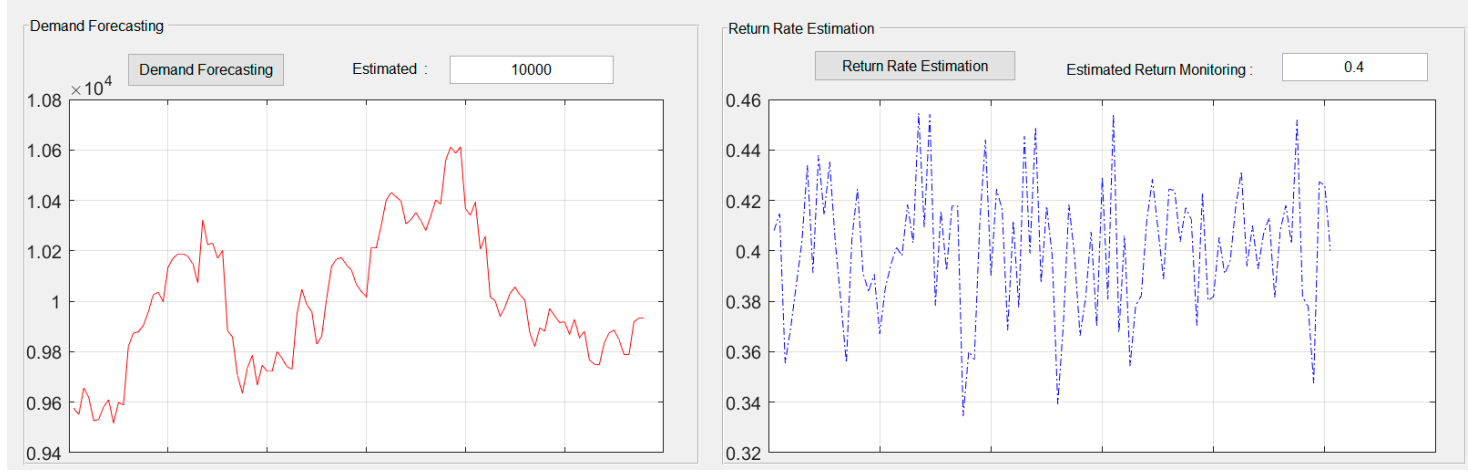

Figure 7. Forecasted demand and estimated return rate.

As shown in Figure 7, the data is analyzed while using various time-series methods. The best fitted model in this scenario is proven to be the ARIMA $(3,1,2)$ model and the prediction is presented while using a Gaussian distribution $\mathrm{N}\left(10,000,23^{2}\right)$. In addition, the current return rate is estimated to be 0.4 . Consequently, to generate the solution of the suggested mathematical programming model, the parameters of the memetic algorithm are inputted to the system.

The solution is then generated and the changes of the objective values plotted, as shown in Figure 8 . 


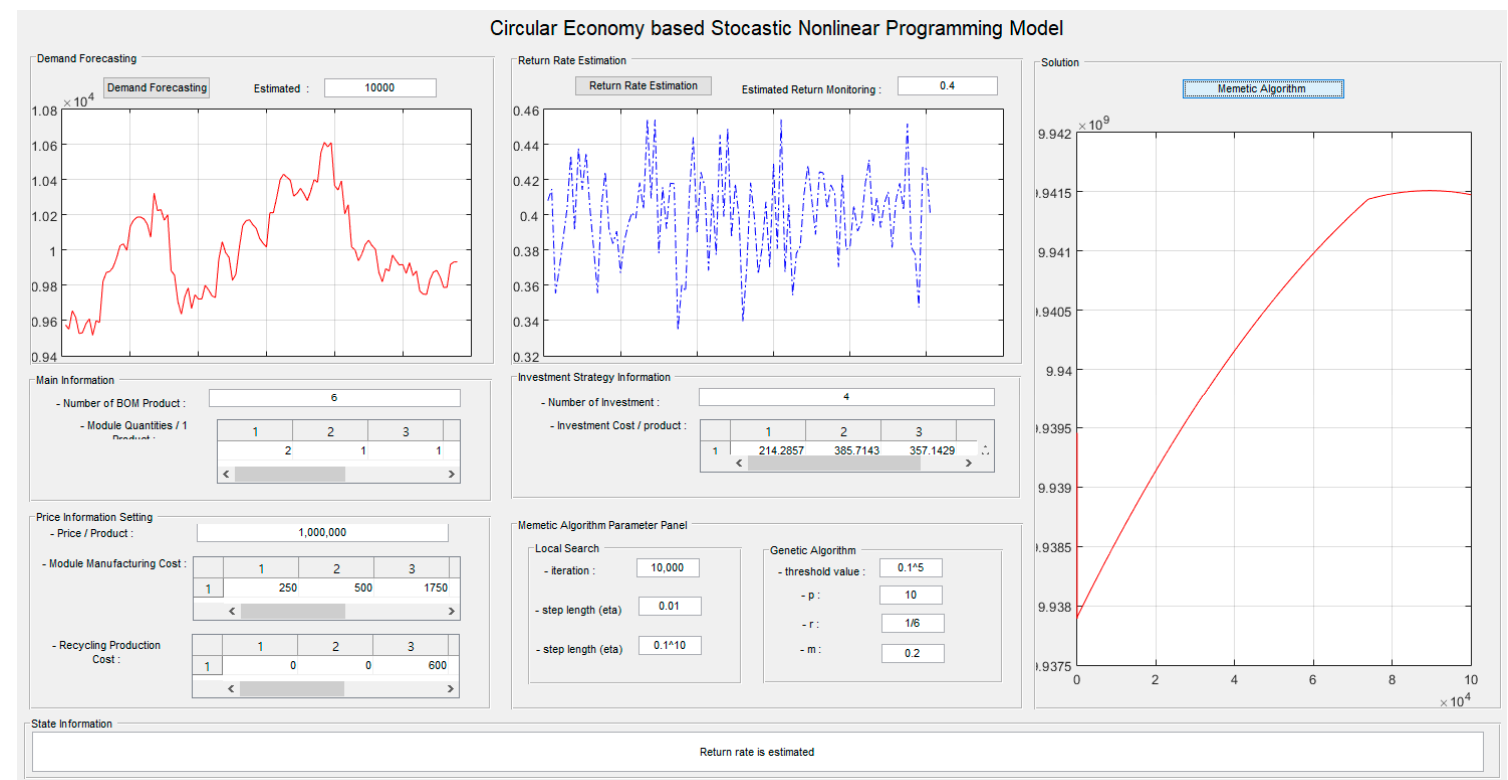

Figure 8. The execution of the process planning and investment framework supporting circular economy.

As illustrated in Figure 8, the objective function value is enhanced and converged to a near-maximum value while using the proposed memetic algorithm. The generated solution supports the circular economy in regard to the fact that the production plan pursues more gathering of recycling components while considering business profits. In addition, it reduces the environmental pollutions due to the use of recycling components.

The solution (Case III) is compared with the other cases to prove the effectiveness of the proposed framework: the case that ignores refurbishing (Case I) and the remanufacturing case barring additional returning investments (Case II). Table 7 provides these solutions and comparisons.

Table 7. The comparisons among three remanufacturing scenarios.

\begin{tabular}{|c|c|c|c|}
\hline Comparisons & Case I & Case II & Case III \\
\hline Main scenario & $\begin{array}{ll}- & \text { production } \\
\text { depends on "newly } \\
\text { manufacturing } \\
\text { components" only }\end{array}$ & $\begin{array}{ll}\text { - } & \text { Using } \\
\text { "reusable modules" } \\
\text { - } \\
\text { additional returning } \\
\text { efforts are ignored }\end{array}$ & $\begin{array}{l}\text { - } \quad \text { additional investments } \\
\text { are considered }\end{array}$ \\
\hline $\begin{array}{l}\text { Profit (under the scenario in } \\
\text { Table 6) }\end{array}$ & $9.89 * 10^{9}$ & $9.91 * 10^{9}$ & $9.94 * 10^{9}$ \\
\hline $\begin{array}{l}\text { Number of Manufacturing } \\
\text { components }\end{array}$ & $\begin{array}{l}{[2000,1000,1000,1000,} \\
2000,1000]\end{array}$ & {$[2000,1000,699,699,1269,699]$} & {$[2000,1000,355,355,432,355]$} \\
\hline $\begin{array}{l}\text { Number of Recycling } \\
\text { components }\end{array}$ & N/A & {$[0,0,301,301,731,301]$} & $\begin{array}{l}{[0,0,137,173,434,137,0,0,148} \\
148,434,148,0,0,53,53,266 \\
53,0,0,355,355,434,355]\end{array}$ \\
\hline $\begin{array}{l}\text { Usage rate of recycling } \\
\text { modules }\end{array}$ & - & $40 \%$ & $82.91 \%$ \\
\hline $\begin{array}{l}\text { Returning rate per each } \\
\text { investment strategy }\end{array}$ & N/A & $\mathrm{N} / \mathrm{A}$ & {$[0.2189,0.0741,0.0982,0.0379]$} \\
\hline
\end{tabular}

The case with additional returning efforts has the largest profit in addition to the largest utilization rate of recycling modules, as shown in Table 7. Based on the analyses, the third scenario that applies the proposed framework has twice the recycling modules keeping the maximal profit compared to the second case. Additionally, it is inferred that the third case might contribute to sustainable manufacturing while using less energy as a result. These results can be differ based on the assumed conditions and parameters. However, the proposed model and the solving framework are considered 
as effective production planning framework that supports circular economy with regards to the additional investment strategies for increased collection, which are evaluated quantitatively under stochastic and nonlinear business environments.

\section{Conclusions and Further Studies}

The circular economy is among the representative trends leading contemporary society. As more efficient business techniques and management methodologies evolve for maximum corporate profits, there has been growing concerns regarding the preservation environments for the future generation, leading to growing with the governmental and municipalities' regulations. These trends have a lot of terminologies, including the circular economy, sustainable engineering, and closed-loop SCM. This paper concentrates on the more active and detailed production planning that supports circular economy. In particular, more focus is put on the decision making for additional investment strategies for recycling products collection. There are existing portfolios for investment strategies, such as promotions, additional installments of gathering facilities, and/or other incentive policies. Existing production planning constraints have to be considered, although these tasks could guarantee more returns of recycling components.

The majority of the circular economy environments have more uncertainties when compared to existing contemporary economies. The uncertainties in returning amount and qualities of recycling modules are also embedded, despite existing contemporary economies having uncertainties in demand and supply abilities and production parameters. Consequently, the circular economy-based production planning has to reflect on the existing planning constraints, additional investments, and more piled uncertainties. This paper proposes a stochastic nonlinear programming model-based production planning framework to solve these issues. In the proposed framework, the demand information is captured through a probability distribution. In addition, the uncertain return rate and the costs of recycling components are represented while using nonlinear function. It is difficult to obtain the exact solution set that meets the circular economy criteria because the framework consists of stochastic and nonlinear characteristics. As a result, this paper presents new and efficient techniques, such as the sample averaging approximation method based on Monte-Carlo method and the memetic algorithm. The use of the Monte-Carlo based sample averaging approximation method helps to handle the uncertainties that are embedded in the circular economy environment. Consequently, the mathematical model is transformed into a Lagrange function while using nonlinear K.K.T. conditions. To generate effective solution sets for the function, the memetic algorithm, which combines Gradient based local search and Genetic algorithm, is utilized. The framework is implemented in a software program supporting circular economy-based production planning in order to prove the effectiveness of the proposed framework in addition to its solving techniques. Thus, its effectiveness is proven through the comparisons of results under various scenarios and analyses. While the proposed framework considers recycling investment framework with uncertain demand and nonlinear recycling cost, this research ignores the suggestion of detailed investment strategies, such as additional network generation or activities for extra efforts. The proposed framework handles these features only in regards to nonlinear costs. Additionally, this research ignores the current integrations of the environmental effects and environment assessments. It is considered that the effectiveness of the proposed framework is enhanced when these assessments are integrated.

As further studies, the broader expansions of the proposed framework are considered. The production planning framework presented particularly focuses on the existing production parameters and extra efforts in the enhancement of the returning rate. The framework covering the overall lifecycle of its supply chain networks is necessary while the current framework handles production planning.

Funding: This work was supported by Priority Research Centers Program through the National Research Foundation of Korea (NRF) funded by the Ministry of Education, Science and Technology (2018R1A6A1A03024003). 
Conflicts of Interest: The author declares no conflict of interest. The funders had no role in the design of the study; in the collection, analyses, or interpretation of data; in the writing of the manuscripts; or in the decision to publish the results.

\section{References}

1. Geissdoerfer, M.; Savaget, P.; Bocken, N.M.P.; Hultink, E.J. The circular Economy-A new sustainability paradigm. J. Clean. Prod. 2017, 114, 11-32. [CrossRef]

2. Bocken, N.M.P.; Pauw, I.D.; Bakker, C.; Grintern, B.V.D. Product design and business model strategies for a circular economy. J. Prod. Eng. 2016, 33, 308-320. [CrossRef]

3. Ghisellini, P.; Cialani, C.; Ulgiati, S. A review on circular economy: The expected transition to a balanced interplay of environmental and economic systems. J. Clean. Prod. 2016, 143, 757-768. [CrossRef]

4. Cullen, J.M. Circular economy: Theoretical benchmark or perpetual motion machine. J. Ind. Ecol. 2017, 21, 483-486. [CrossRef]

5. Bocken, N.M.P.; Olivetti, E.A.; Cullen, J.M.; Potting, J.; Lifset, R. Taking the circularity to the next level: A special issue on the circular economy. J. Ind. Ecol. 2017, 21, 479-482. [CrossRef]

6. Ellen MacArthur Foundation. What Is a Circular Economy? Available online: https://www. ellenmacarthurfoundation.org/circular-economy/concept (accessed on 15 May 2019).

7. Ness, D.; Xing, K. Toward a resource-efficient built environment: A literature review and conceptual model. J. Ind. Ecol. 2017, 21, 572-592. [CrossRef]

8. Hollander, M.C.D.; Bakker, C.A.; Hultink, E.J. Product design in circular economy: Development of a typology of key concepts and terms. J. Ind. Ecol. 2017, 21, 517-525. [CrossRef]

9. Mendoza, J.M.F.; Sharmina, M.; Gallego-Schmid, A.; Heyes, G.; Azapagic, A. Integrating backcasting and eco-deisgn for the ciruclar economy: The BECE Framework. J. Ind. Ecol. 2017, 21, 526-544. [CrossRef]

10. Sabaskan, R.C.; Bhattacharya, S.; Wassenhove, L.N. Closed-loop supply chain models with product remanufacturing. Manag. Sci. 2004, 50, 239-252. [CrossRef]

11. Kim, J.; Kim, T.; Lee, H. Strategic pricing framework for closed loop supply chain with remanufacturing process using nonlinear fuzzy function. J. Soc. Korea Ind. Syst. Eng. 2017, 40, 29-37. [CrossRef]

12. Ghahremani-Nahr, J.; Kian, R.; Sabet, E. A robust fuzzy mathematical programming model for the closed-loop supply chain network design and a whale optimization solution algorithm. Expert Syst. Appl. 2019, 116, 454-471. [CrossRef]

13. Hashemi, V.; Chen, M.; Fang, L. Modeling and analysis of aerospace remanufacturing systems with scenario analysis. Int. J. Adv. Manuf. Technol. 2016, 87, 2135-2151. [CrossRef]

14. Pishvaee, M.S.; Torabi, S.A. A possibilistic programming approach for closed-loop supply chain network design under certainty. Fuzzy Sets Syst. 2010, 161, 2668-2683. [CrossRef]

15. Turki, S.; Didukh, S.; Sauvey, C.; Rezg, N. Optimization and analysis of a manufacturing-remanufacturing-transport-warehousing system within a closed-loop supply chain. Sustainability 2017, 9, 561. [CrossRef]

16. Shakourloo, A. A multi-objective stochastic goal programming model for more efficient remanufacturing process. Int. J. Adv. Manuf. Technol. 2017, 91, 1007-1021. [CrossRef]

17. Linder, M.; Sarasini, S.; Loon, P.V. A metric for quantifying product-level circularity. J. Ind. Ecol. 2017, 21, 545-558. [CrossRef]

18. Reike, D.; Vermeulen, W.J.V.; Witjes, S. The circular economy: New or refurbishing as CE 3.0?-Exploring controversies in the conceptualization of the circular economy through a focus on history and resource value retention options. Resour. Conserv. Recycl. 2018, 135, 246-264. [CrossRef]

19. Jelinski, L.W.; Graedel, T.E.; Laudise, R.A.; McCall, D.W.; Patel, C.K.N. Industrial ecology: Concepts and approaches. Proc. Natl. Acad. Sci. USA 1992, 89, 793-797. [CrossRef]

20. Birge, J.R.; Louveaux, J. Introduction to Stochastic Programming; Springer: New York, NY, USA, 2011.

21. Gutjahr, W.J. Recent trends in metaheuristics for stochastic combinatorial optimization. Cent. Eur. J. Comput. Sci. 2011, 1, 58-66. [CrossRef]

22. Cheng, C.; Sa-Ngasoongsong, A.; Beyca, O.; Le, T.; Yang, H.; Kong, Z.; Bukkapatnam, S.T.S. Time series forecasting for nonlinear and non-stationary processes: A review and comparative study. IIE Trans. 2015, 47, 1053-1071. [CrossRef] 
23. Li, N.; Felix, T.S.; Chung, S.H.; Niu, B. The impact of non-stationary demand and forecasting on a failure-prone manufacturing system. In Proceedings of the 2015 International Conference on Industrial Engineering and Operations Management, Dubai, UAE, 3-5 March 2015; pp. 1-7.

24. Vendemia, W.G.; Patuwo, B.E.; Hung, M.S. Evaluation of lead time in production/inventory systems with non-stationary stochastic demand. J. Oper. Res. Soc. 1995, 46, 221-233. [CrossRef]

25. Sakalauskas, L. Nonlinear stochastic optimization by the Monte-Carlo method. Informatica 2000, 11, 455-468.

26. Shapiro, A. Monte Carlo simulation approach to stochastic programming. In Proceedings of the 2001 Winter Simulation Conference, Arlington, VA, USA, 9-12 December 2001; pp. 428-431.

27. Casella, G.; Berger, R.L. Statistical Inference; Duxbury: Bolinas, CA, USA, 2001.

28. Shapiro, A. Monte Carlo sampling approach to stochastic programming. ESAIM Proc. 2003, 13, 65-73. [CrossRef]

29. Williams, D. Probability with Martingales; Cambridge Mathematical Textbooks: Cambridge, UK, 1991.

30. Kleywegt, A.J.; Shapiro, A.; Homem-de-Mello, T. The sample average approximation method for stochastic discrete optimization. SIAM J. Optim. 2001, 12, 479-502. [CrossRef]

31. Mostcato, P. On Evolution, Search, Optimization, Genetic Algorithms and Martial Arts: Towards Memetic Algorithms. In Caltech Concurrent Computation Program Report; Caltech: Pasadena, CA, USA, 1989.

32. Zhu, Z.; Wang, F.; He, S.; Sun, Y. Global path planning of mobile robots using a memetic algorithm. Int. J. Syst. Sci. 2015, 46, 1982-1993. [CrossRef]

33. Chen, X.S.; Ong, Y.S.; Lim, M.H.; Tan, K.C. A multi-facet survey on Memetic computation. IEEE Trans. Evol. Comput. 2011, 15, 591-607. [CrossRef]

34. Neri, F.; Cotta, C. Memetic algorithms and memetic computing optimization: A literature review. Swarm Evol. Comput. 2012, 2, 1-14. [CrossRef]

35. Choo, S.; Lee, H. Learning framework of multimodal Gaussian-Bernoulli RBM handling real-value input data. Neurocomputing 2018, 275, 1813-1822. [CrossRef]

36. Mitchell, T.M. Machine Learning; McGraw-Hill: New York, NY, USA, 1997.

(C) 2019 by the author. Licensee MDPI, Basel, Switzerland. This article is an open access article distributed under the terms and conditions of the Creative Commons Attribution (CC BY) license (http://creativecommons.org/licenses/by/4.0/). 